\title{
De novo expression of the class-A macrophage scavenger receptor conferring resistance to apoptosis in differentiated human THP-1 monocytic cells
}

\author{
Hai-Sun Liao ${ }^{1}$, Akiyo Matsumoto ${ }^{2}$, Hiroshige Itakura ${ }^{2}$, Tamara \\ Pittman $^{1}$,Tatsushiko Kodama ${ }^{2}$ and Yong-Jian Geng ${ }^{\star, 1}$ \\ ${ }^{1}$ Cardiovascular and Pulmonary Research Institute, Allegheny University of the \\ Health Sciences, Pittsburgh, Pennsylvania, USA \\ 2 Department of Molecular Biology and Medicine, University of Tokyo, Tokyo, \\ Japan \\ * corresponding author: Yong-Jian Geng, MD, PhD, Cardiovascular and \\ Pulmonary Research Institute, Allegheny University of the Health Sciences, \\ 320 East North Avenue, Pittsburgh, PA 15212, USA . tel: 412-359-8228; \\ fax: 412-359-8257; e-mail: ygeng@pgh.auhs.edu
}

Received 19.8.98; revised 21.10.98; accepted 25.11.98 Edited by $\mathrm{G}$. Ciliberto

\begin{abstract}
The class-A macrophage scavenger receptor (MSR) is a trimeric multifunctional protein expressed selectively in differentiated monomyeloid phagocytes which mediates uptake of chemically modified lipoproteins and bacterial products. This study investigated whether MSR plays a role in the regulation of apoptosis, a model of genetically programmed cell death. De novo expression of MSR occurred in human THP-1 monocytic cells differentiated with phorbol esters, which activated a nuclear transcription factor binding to the Ap1/ets-like domain of the MSR promoter. The phorbol ester-stimulated THP-1 cells also expressed increased levels of the pro-apoptotic gene products, caspase-3 and Fas ligand, but the cells exhibited no change in apoptosis. Global activation of GTP-binding proteins with fluoride anions triggered apoptosis of THP-1 cells in a time- and concentration-dependent manner, demonstrated by nuclear shrinkage and fragmentation and internucleosomal DNA fragmentation. However, the MSR-expressing THP-1 macrophage-like cells showed a significant reduction in apoptosis compared to undifferentiated control THP-1 cells, which produce MSR at undetectable levels. Fluoride stimulation also triggered apoptosis of human Jurkat T cells. Stimulation with phorbol ester made no difference in apoptosis between treated and untreated Jurkat cells. Finally, Chinese hamster ovary (CHO) cells overexpressing the class-A MSR type I by CDNA transfection showed markedly increased resistance to Gprotein-coupled apoptosis. Thus, de novo expression of MSR associated with monocyte maturation into macrophages appears to confer the resistance of macrophages to apoptotic stimulation by G-protein activation.
\end{abstract}

Keywords: macrophages; apoptosis; scavenger receptors; G-protein; atherosclerosis
Abbreviations: MSR, macrophage scavenger receptor; $\mathrm{NaF}$, sodium fluoride; LDL, low density lipoprotein; PMA, phorbol 12myristate 13-acetate; PMSF, phenylmethysulfonyl fluoride; OxLDL, oxidized low-density lipoprotein; TUNEL, terminal deoxyribonucleotide transferase (TdT)-mediated dUTP nick end labeling

\section{Introduction}

The class-A macrophage scavenger receptor (MSR), a trimeric membrane glycoprotein, mediates recognition and internalization by macrophages of chemically modified lipoproteins such as acetylated and oxidized low-density lipoprotein (oxLDL). ${ }^{1,2}$ The MSR-mediated uptake of modified LDL promotes intracellular accumulation of lipids, particularly cholesterol and cholesteryl esters, leading to the transformation of macrophages or other MSR-bearing cells into lipidladen foam cells in atherosclerosis, an arterial disease that can cause cardiac and cerebral infarction. In addition to the modified lipoproteins, MSR recognizes and binds other macromolecules with clustered negative charges, including the bacterial product lipopolysaccharide or endotoxin ${ }^{3}$ and certain polyanionic compounds. ${ }^{4}$ The clearance of bacterial products mediated by the class-A MSR plays an important role in protecting the host against lethal endotoxin shock. ${ }^{5}$ MSR also participates in adhesive interactions between lymphocytes and macrophages as well as the macrophageto-matrix adhesion. ${ }^{6}$ Recently, this receptor has been identified $^{7}$ as one of the primary membrane molecules responsible for macrophage recognization and engulfment of cells undergoing apoptosis, a model of genetically programmed cell death. Thus, MSR functions not only as a scavenger of modified lipoproteins but also participates in innate immune responses.

The class-A MSR is selectively expressed in the monomyeloid cell phagocytes or macrophages. Tissue known to comprise numbers of macrophages [e.g., the lymph nodes ${ }^{9}$ and atherosclerotic plaques ${ }^{10}$ ] can produce abundant MSR proteins. The receptor expression usually occurs in the later stages of differentiation of monocytes into macrophages and is thus regarded as a marker of monomyeloid cell differentiation. Indeed, monocytes circulating in peripheral blood do not produce MSR at any appreciable level, although MSR is dramatically induced when monocytes enter tissue and differentiate into macrophages. ${ }^{10,11}$ At least two isoforms of the class-A MSR (types I and II) have been characterized in human monocyte-derived macrophages, which are generated by the alternative splicing of a single MSR gene. ${ }^{11-13}$ Mature macrophages express both isoforms of the class-A MSR, which have a similar affinity with their lipoprotein ligand. A great diversity of environmental factors can regulate 
expression of MSR, including growth factors, proinflammatory cytokines, and transforming agents with the property of influencing macrophage differentiation and activation. For instance, macrophage colony-stimulating factor ${ }^{14}$ promotes MSR expression in human monocyte-derived macrophages while interferon- $\gamma^{15}$ and tumor necrosis factor ${ }^{16,17}$ suppress it.

Human THP-1 monocytic cells have been widely employed as an in vitro model for investigating the molecular mechanisms underlying monocyte-to-macrophage differentiation. In exposure to the transforming agent, phorbol esters, that activates protein kinase $\mathrm{C}$ (PKC), THP-1 cells mature into macrophage-like cells with de novo expression of MSR. The nuclear transcription proteins, PU.1, Ap-1, and a cooperating ets-domain, can recognize the sequence of the MSR promoter, which may be responsible for transcriptional regulation of MSR expression. ${ }^{18-21}$

Apoptosis is a major determiner of tissue cellularity and cell lifespan. It is known that circulating monocytes spontaneously undergo apoptosis unless they transform into macrophages. This monocyte death process is highly regulated by many environmental factors, such as inflammatory mediators and growth factors. ${ }^{22-24}$ In contrast to their precursor monocytes, which frequently undergo apoptosis, tissue mature macrophages are longlived cells that tolerate many apoptotic stimuli, such as antineoplastic drugs and ionizing radiation. Both monocytes and macrophages have been reported to express products of apoptosis-regulating genes, including some members in the caspase gene family and in the Bcl-2 gene family. ${ }^{25}$ In culture, human monocytes undergo apoptosis when Fas, a member of the tumor necrosis factor receptor/nerve growth factor receptor family, is ligated with its ligand (FasL). Although monocyte-derived macrophages also express both Fas and its ligand, ${ }^{25,26}$ they appear resistant to the death signals delivered by the Fas-Fas ligand deathsignaling pathway. On the other hand, macrophages are sensitive to apoptosis triggered by activation of GTPbinding proteins (G-protein). The global activator of GTPbinding proteins, fluoride anions, can trigger apoptosis in rat macrophages. ${ }^{27}$ The apoptosis-promoting effect of fluoride anions may occur through activation of heterotrimeric Gproteins. $^{28}$

The different susceptibility to apoptosis between monocytes and macrophages points to the possibility that certain molecules associated with macrophage differentiation may regulate apoptosis of macrophages. MSR expression represents a late-stage marker of monocyte-macrophage differentiation. Macrophages bearing this receptor can survive cytotoxic attack by many extracellular cytotoxic macromolecules, including oxidized LDL and bacterial products, e.g., endotoxin. ${ }^{5}$ Thus, it is important to clarify whether MSR contributes to the resistance of tissue macrophages to the apoptotic attack from cytotoxic factors of both extra-and intracellular environments.

To address this issue, in this study, we examined whether MSR and other known death-regulating gene products $^{29}$ (e.g., caspase-3 or CPP32, ${ }^{30}$ Fas/Fas ligand ${ }^{26}$ and $\mathrm{BCl} 2^{31}$ exert regulatory effects on apoptosis of macrophages. We observed that differentiated THP-1 macrophages with de novo expression of the class-A MSR, as well as MSR cDNA-transfected Chinese hamster ovary $(\mathrm{CHO})$ cells showed markedly increased resistance to apoptosis triggered by activation of G-proteins, indicating an inhibitory effect of MSR on macrophage apoptosis.

\section{Results}

\section{De novo expression of MSR in PMA-differentiated THP-1 cells}

To determine the activities of the transcription factors in the nuclei, we extracted nuclear proteins from human THP-1 cells treated or not with PMA. Examination of the complex of the MSR promoter probe with the Ap-1/ets-like nuclear transcription factor by EMSA showed that nuclear proteins extracted from untreated, control THP-1 cells contained no signal for the complex formation (Figure 1), indicating that the MSR transcription factor activity was not appreciable in the control. In contrast, THP-1 cells treated with PMA for $16 \mathrm{~h}$ clearly showed the signal for formation of the complex of the probe with the nuclear transcription factor from THP-1 cells (Figure 1). For control studies, we also performed EMSA on human Jurkat $T$ cells with the same probe. We found that neither PMA-treated nor control Jurkat cells exhibited the same nuclear protein binding activity toward the MSR probe at

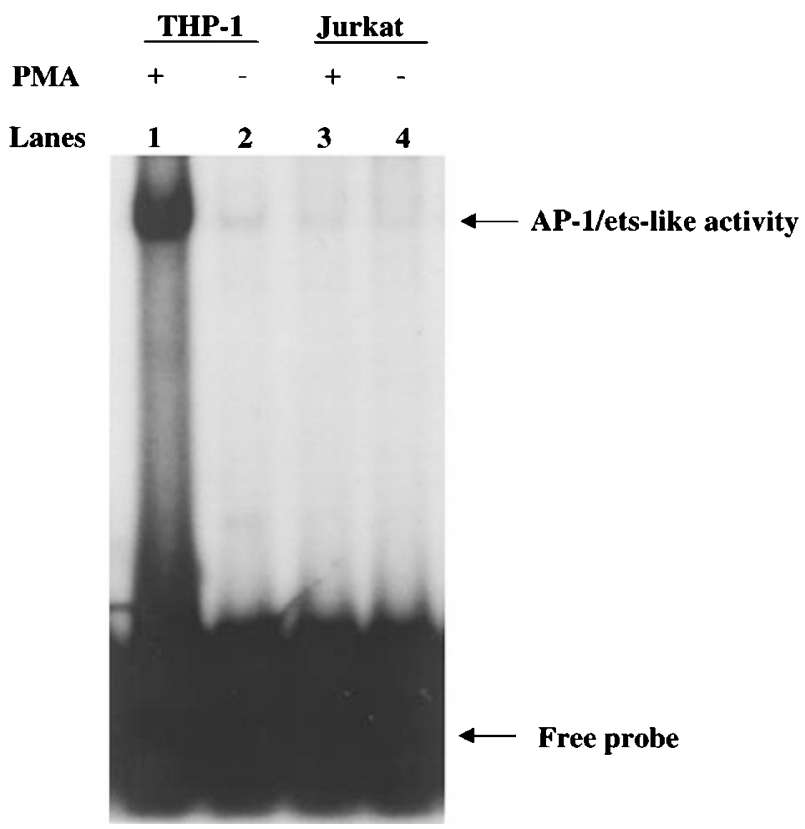

Figure 1 Activation of the MSR Ap-1/ets-like nuclear transcription factor in human THP-1 and Jurkat cells treated with PMA. THP-1 and Jurkat cells were treated with or without PMA $(100 \mathrm{nM})$ for $16 \mathrm{~h}$. After the treatment, nuclear proteins were then extracted from the cells, and then incubated with ${ }^{32} \mathrm{P}$. labeled oligonucleotide encoding the sequence of Ap-1/ets-like cis-element in the MSR gene promoter. Electrophoresis of the labeled nuclear proteins was performed in 6\% PAGE. Lane 1, untreated THP-1 cells; lane 2, PMA-treated THP-1 cells; lane 3, untreated Jurkat cells; and lane 4, PMA-treated Jurkat cells 
any appreciable level (Figure 1). Thus, the activity of MSR nuclear transcription factor was expressed selectively in the PMA-treated monomyeloid cells.

To determine the MSR transcriptional levels, we further analyzed MSR mRNA using RNase protection assay. Total RNA isolated from THP-1 and Jurkat cells was hybridized with ${ }^{32} \mathrm{P}$-labeled cRNA probes for MSR types I and II. After removing single-strand RNA with RNase $A / T 1$, the labeled double-strand MSR transcripts were demonstrated by electrophoresis, followed by autoradiography. In agreement with the results of EMSA, the RNase protection assay demonstrated the expression of both MSR type-I and -II transcripts in PMA-treated but not untreated control THP-1 cells (Figure 2a). Both PMA-treated and untreated Jurkat $T$ cells expressed no signals for the MSR mRNA (Figure 2a), indicating the selectivity of the MSR transcription factor activation.

Immunoblotting with monoclonal antibody directed against MSR showed the presence of trimeric MSR at approximately $220 \mathrm{kDa}$ in the PMA-treated THP-1 cells but not Jurkat cells (Figure 2c). The surface expression of MSR on THP-1 cells was quantitated by immunofluorescent flow cytometry with the same anti-MSR antibody. Figure 3 shows a significant $(P<0.05)$ increase in the MSR fluorescent intensity in THP-1 cells treated with PMA. The

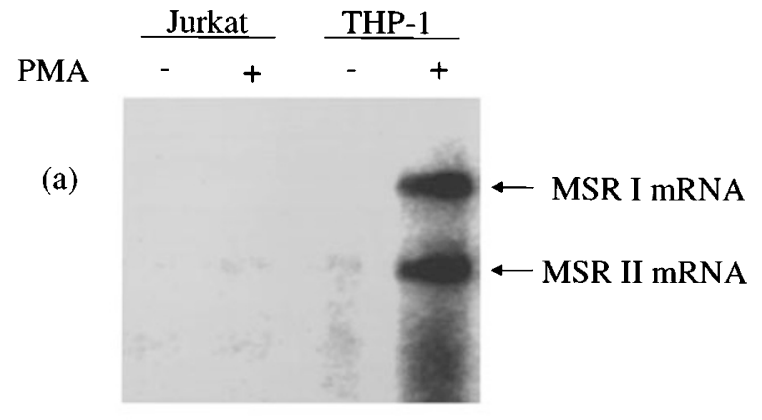

(b)

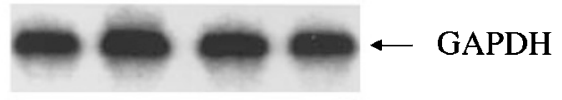

(c)

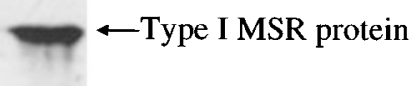

Figure 2 Expression of MSR mRNA and protein in THP-1 and Jurkat cells treated with or without PMA. Total RNA was isolated from human THP-1 and Jurkat cells treated with or without PMA $(100 \mathrm{nM})$ for $48 \mathrm{~h}$ using acidic phenol/ chloroform/guanidinium thiocyanate extraction, and hybridized with ${ }^{32} \mathrm{P}$ labeled CRNA probes for MSR types I and II synthesized from linearized plasmids containing the MSR type I and II cDNA, respectively. After digestion of single-strand RNA with RNases A and T-1, the MSR mRNA hybridized with the probes was detected by electrophoresis on denatured gels followed by autoradiography. For determination of equal loading of mRNA, a cRNA probe for GAPDH was used. Total proteins $(30 \mu \mathrm{g})$ extracted from THP-1 cells were separated on $7.5 \%$ SDS-PAGE. After electrophoresis, proteins were transferred onto membrane and probed with monoclonal anti-MSR. Peroxidase-anti-mouse $\lg$ was used as the second antibody. Lane 1, untreated Jurkat cells; lane 2, PMA-treated Jurkat cells; lane 3, untreated THP-1 cells; and lane 4, PMA-treated THP-1 cells. (a) RNase protection assay for MSR; (b) RNase protection assay for GAPDH; (c) Immunoblotting assay for MSR percentage of Dil-AcLDL positive cells increased by $>50 \%$ after stimulation with PMA. In contrast, untreated THP-1 cells and PMA-treated Jurkat cells did not produce this signal.

\section{Differentiated THP-1 cells with increased expression of caspase-3 and Fas ligand}

To determine if death-regulating gene products such as caspase-3, FADD, Bcl-2, and FasL regulate apoptosis of macrophages, total cellular proteins were extracted from PMA treated and untreated THP-1 cells and subjected to immunoblotting assays. In culture, THP-1 cells spontaneously produced FasL, FADD, and Bcl2, as demonstrated by immunoblotting (Figure 4). In untreated cultures, THP-1 cells produced little caspase-3, but treatment with $100 \mathrm{nM}$ PMA for $48 \mathrm{~h}$ markedly induced expression of caspase-3. This treatment also enhanced FasL production by the cells (Figure 4). However, PMA-treated THP-1 cells appeared to have little influence on expression of FADD and Bcl-2. No major differences in caspase-3 and FasL occurred between PMA-treated and untreated Jurkat cells (data not shown). Flow cytometry showed more than $50 \%$ of the THP-1 cells became caspase- 3 positive, and the fluorescent intensity for FasL increased by approximately $40 \%$ after treatment with $100 \mathrm{nM}$ PMA for $48 \mathrm{~h}$. However examination of cell viability revealed that the percentage of viable cells in the PMAtreated cultures remained similar to that of untreated cultures (both more than 95\%). Thus, despite the increased expression of the death-promoting proteins, caspase-3 (CPP32) and FasL, the PMA-differentiated THP-1 monocytic cells survived without any considerable changes in apoptosis.

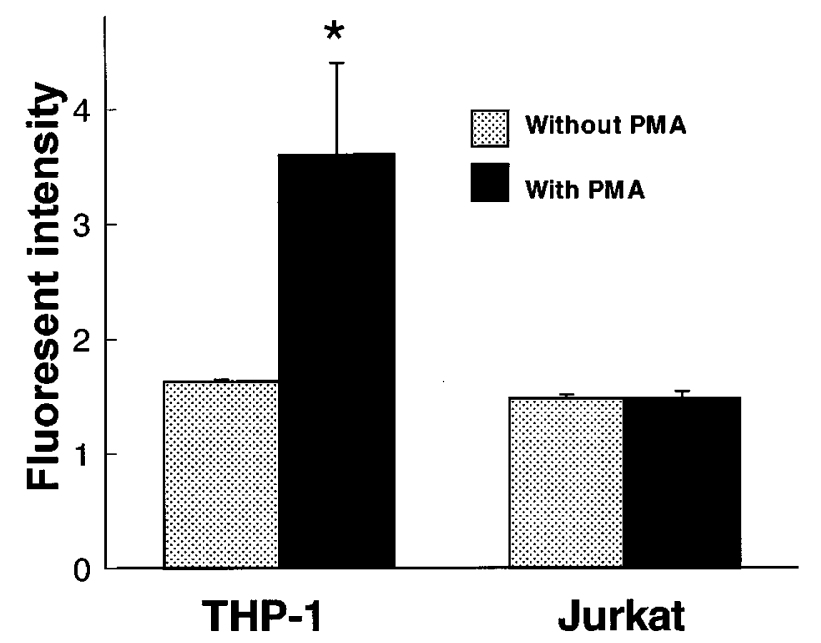

Figure 3 Immunofluorescent flow cytometry of MSR on PMA-treated or untreated THP-1 cells. THP-1 cells treated with or without PMA $(100 \mathrm{nM})$ for $48 \mathrm{~h}$ were stained with anti-MSR antibody $(1: 150)$. Cells were washed and incubated with FITC anti-mouse IgG. Counternuclear staining was performed by using propidium iodide $(5 \mu \mathrm{g} / \mathrm{ml})$. The immunostains were assessed on the FACScalibur flow cytometer. FITC fluorescent intensity of MSR was recorded in FL1 channel and analyzed using the Cellquest program 
(a) CPP-32

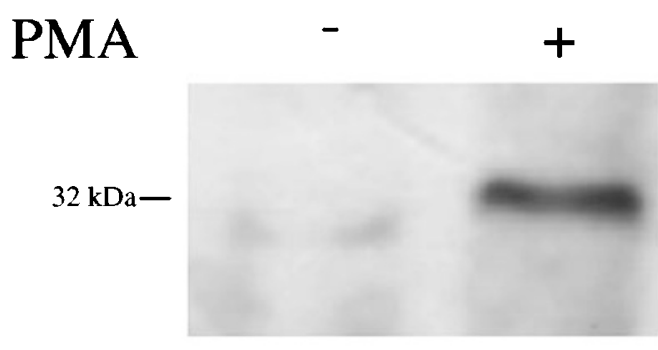

(c) $\mathrm{Bcl}-2$

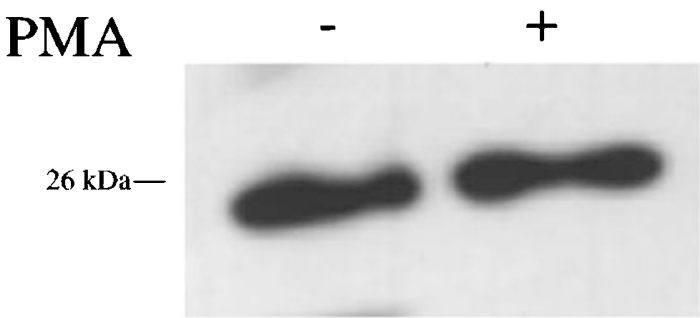

(b) FADD

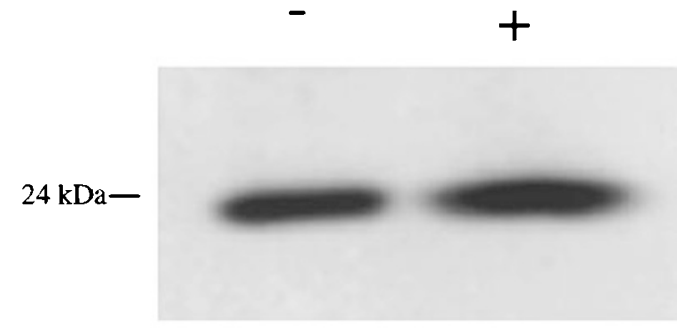

(d) Fas-ligand

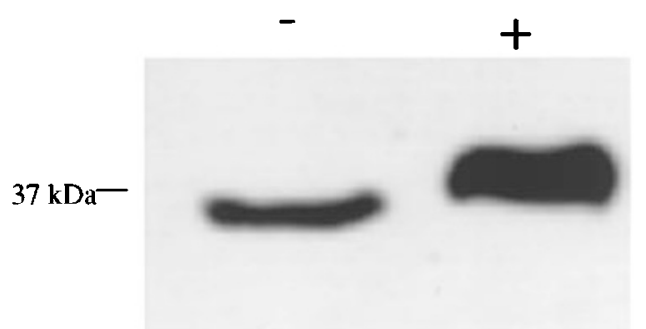

Figure 4 Expression of CPP32, FADD, Fas ligand and Bcl-2 in PMA-treated and untreated THP-1 cells. Total proteins ( $30 \mu \mathrm{g} / \mathrm{ml})$ from THP-1 cells treated with or without PMA (100 nM) for $48 \mathrm{~h}$ were separated by electrophoresis on SDS-PAGE. After electrophoresis, proteins were transferred onto membranes, blocked and incubated with antibodies to CPP32, FADD, FasL and Bcl-2, respectively. (a) anti-CPP32; (b) anti-FADD; (c) anti-FasL; and (d) anti-Bcl-2

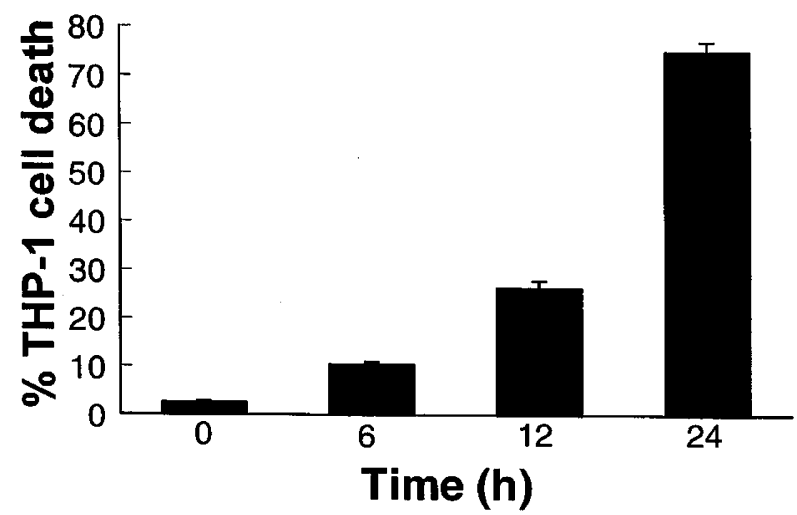

Figure 5 Time-dependent induction of cell death by fluoride anion in THP-1 monocytic cells. THP-1 cells treated with $\mathrm{NaF}(4 \mathrm{mM})$ for $0,6,12$ and $24 \mathrm{~h}$ were stained with a combination of acridine orange and ethidium bromide. The percentage of dead cells was calculated by dividing the number of non-viable cells by total cell number. Data represent means \pm S.D. $(n=3)$

\section{Induction of apoptosis by activation of G-proteins with fluoride anions}

Fluoride anions, a global activator of GTP-binding proteins, can trigger apoptosis in rat alveolar macrophages. ${ }^{27}$ The proapoptotic effect of fluoride anions is thought to operate through a signaling transduction system composed of the heterotrimers of G-proteins in the cellular membrane. ${ }^{28} \mathrm{We}$ therefore examined whether stimulation with $\mathrm{NaF}$ triggers apoptosis of human THP-1 monocytic cells. Cell viability was determined by staining with a combination of the DNA-binding fluorochromes acridine orange and ethidium bromide. In the control cultures, few THP-1 cells ( $<5 \%)$ appeared non-viable. However, treatment with $\mathrm{NaF}$ induced a significant reduction $(P<0.05)$ in viability of THP-1 cells in a time-dependent (Figure 5) and concentration-dependent manner (Figure 6). With elevation of $\mathrm{NaF}$ concentrations from $0-5 \mathrm{mM}$, the percentage of viable cells declined from nearly $95 \%$ to less than $20 \%$ (Figure 6a). Under the same conditions, $\mathrm{NaF}$ treatment resulted in Jurkat cell death at similar levels (Figure $6 b)$, suggesting that in culture, THP-1 and Jurkat cells shared the same sensitivity to the apoptotic attack by flouride anions.

To confirm that the NaF-induced cell death was apoptotic, morphology of the NaF-treated THP-1 cells was analyzed by confocal scanning microscopy. Staining with a combination of acridine orange and ethidium bromide provided images of cells undergoing apoptosis. Living cells showed green nuclei with homogenous distribution of chromatin, while dead cells contained condensed or shrunken nuclei, which emitted red fluorescence (Figure 7). The non-viable cells showed nuclear morphological alterations characteristic of apoptosis including shrinkage, chromatin patching and nuclear fragmentation. In addition, most of the cells retained intact cellular membrane, suggesting that they underwent apoptosis rather than necrosis.

Internucleosomal DNA fragmentation biochemically characterizes apoptosis. We therefore examined the size of genomic DNA isolated from THP-1 and Jurkat cells. Agarose gel electrophoresis demonstrated the appearance 
(a)

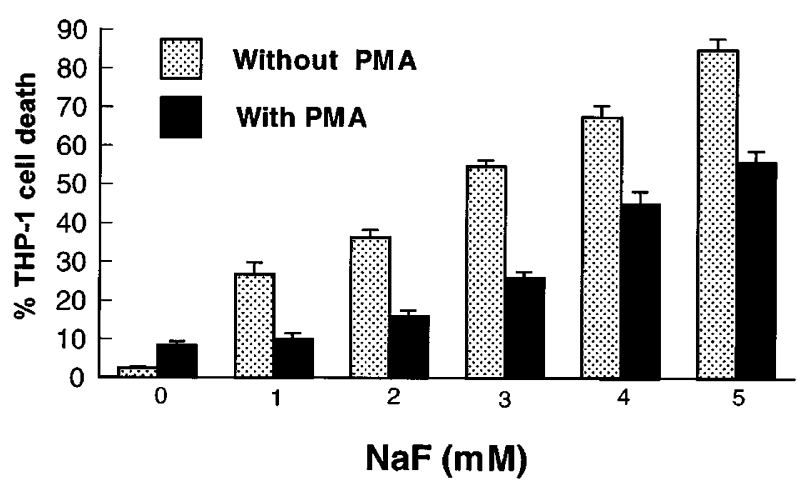

(b)

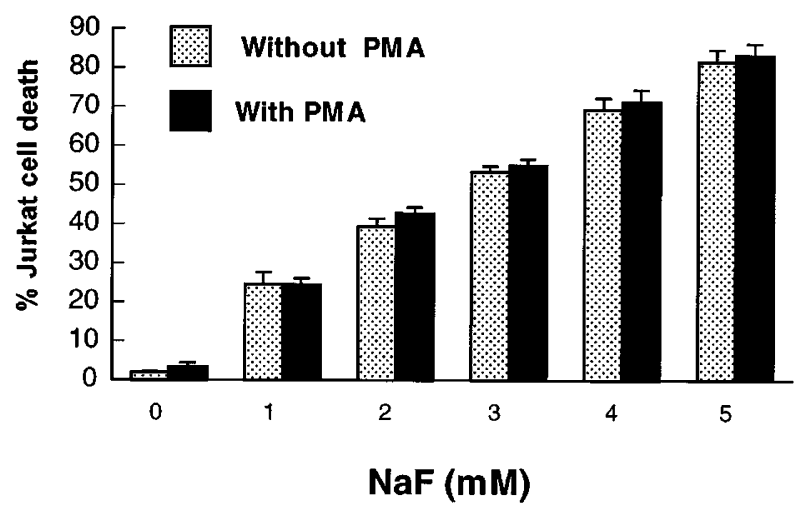

Figure 6 Concentration-dependent alterations in the viability of PMApretreated and untreated THP-1 and Jurkat cells when exposed to fluoride anions. THP-1 and Jurkat cells pretreated with or without PMA (100 nM) for $48 \mathrm{~h}$ were exposed to $0,1,2,3,4$ and $5 \mathrm{mM} \mathrm{NaF}$ for $24 \mathrm{~h}$. Cell viability was determined by staining with a combination of acridine orange and ethidium bromide. More than 200 cells were counted for each sample. The percentage of dead cells was calculated by dividing the number of dead cells by the total cell number. Data represent means \pm S.D. of three experiments. (a) concentration-dependent change in the viability of THP-1 cells exposed to Naf; (b) concentration-dependent alteration in the viability of Jurkat cells

of DNA fragments at about $180-200 \mathrm{bp}$ or multiples in both THP-1 and Jurkat cells in a pattern also dependent on the concentrations of $\mathrm{NaF}$ (Figure 8). Little fragmentation of DNA was found in untreated control THP-1 and Jurkat cells (Figure 8). Nuclear DNA fragmentation was further confirmed by in situ $3^{\prime}$ end-labeling of DNA fragments or the TUNEL technique in the NaF-treated cells. Thus, treatment with fluoride anions induced apoptosis of human THP-1 cells.

\section{Resistance to G-protein-coupled apoptosis in PMA-pretreated, MSR-expressing THP-1 cells}

To determine whether MSR expression influenced apoptosis of macrophages, we next determined whether there was a difference in apoptosis between MSR-expressing and MSR-

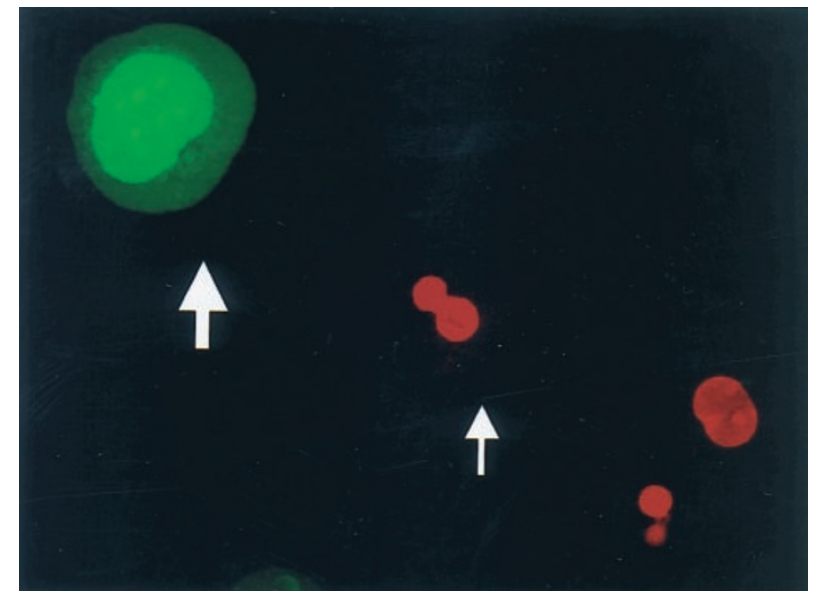

Figure 7 Confocal scanning microscopy of THP-1 cells exposed to fluoride anions. THP-1 cells cultured in RPMI- 1640 media were treated with $5 \mathrm{mM} \mathrm{NaF}$ for $24 \mathrm{~h}$. The cells were stained with acridine orange and ethidium bromide for $5 \mathrm{~min}$, and then visualized under a Bio-Rad confocal scanning microscopy. Living cells showed green fluorescence in their nuclei, while dead cells displayed red fluorescent nuclei. Note that the dead cells had shrunk or fragmented nuclei with chromatins condensation

negative cells. Both THP-1 and Jurkat cells pretreated with PMA for $48 \mathrm{~h}$ were exposed to different concentrations of $\mathrm{NaF}$. We observed that PMA-pretreated, MSR-expressing THP-1 cells showed significantly higher viability than untreated, MSR negative THP-1 cells (Figure 6a), suggesting that the PMA-pretreated, MSR-expressing THP-1 cells were less sensitive to the apoptotic stimulus. DNA agarose gel electrophoresis also showed a decline in internucleosomal DNA fragmentation in the PMA-pretreated THP-1 cells (Figure $8 \mathrm{a})$, consistent with the results from the assays of cell viability.

Human Jurkat $T$ cells did not express MSR at any detectable levels even in exposure to PMA (Figure 2). Similar to THP-1 cells, they underwent apoptosis after stimulation with $\mathrm{NaF}$ (Figures $6 \mathrm{~b}$ and $8 \mathrm{~b}$ ). We therefore employed Jurkat cells as the control to determine whether PMA-pretreatment might also prevent apoptosis in Jurkat cells. In comparison with untreated cells, PMA-treated Jurkat cells showed reductions in both cell viability and DNA fragmentation at almost the same levels (Figures $6 \mathrm{~b}$ and $8 b$ ), indicating no difference in the sensitivity to apoptosis between PMA-treated and untreated Jurkat cells. This indicates that PMA stimulation or activation of protein kinase $C$ itself is not sufficient to block apoptosis of the cells triggered by activation of G-proteins.

\section{Transfection with MSR cDNA conferring resistance of $\mathrm{CHO}$ cells to apoptosis}

To further verify that MSR expression prevents apoptosis, stable expression of MSR in $\mathrm{CHO}$ cells was established by transfection with MSR type I cDNA. The MSR-expressing $\mathrm{CHO}$ cells were exposed to fluoride anions. Microscopic analysis clearly showed that activation of G-proteins by exposure to fluoride anions induced marked morphological alterations, including cell shrinkage, detachment, and 


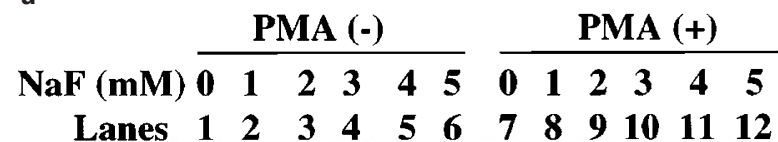

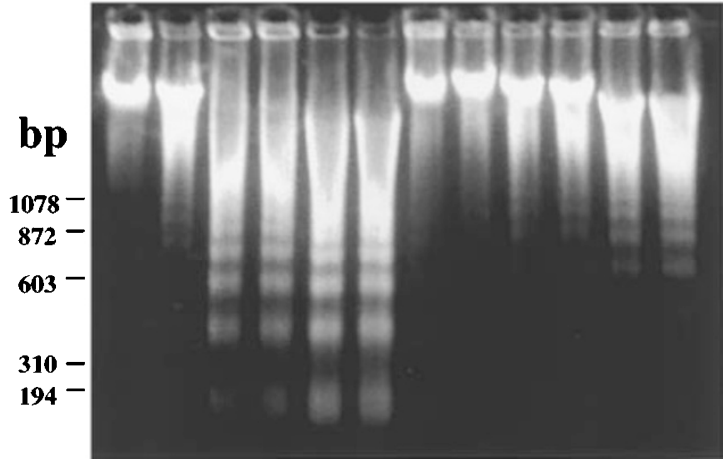

b

\begin{tabular}{|c|c|c|c|c|c|c|c|c|c|c|c|}
\hline \multirow[b]{2}{*}{$\mathrm{NaF}(\mathrm{mM})$} & \multicolumn{5}{|c|}{ PMA (-) } & \multicolumn{6}{|c|}{ PMA (+) } \\
\hline & 1 & 2 & 3 & 4 & 5 & 0 & 1 & & 3 & 4 & 5 \\
\hline Lanes & 2 & 3 & 4 & 5 & 6 & 7 & 8 & & 10 & 11 & 17 \\
\hline
\end{tabular}

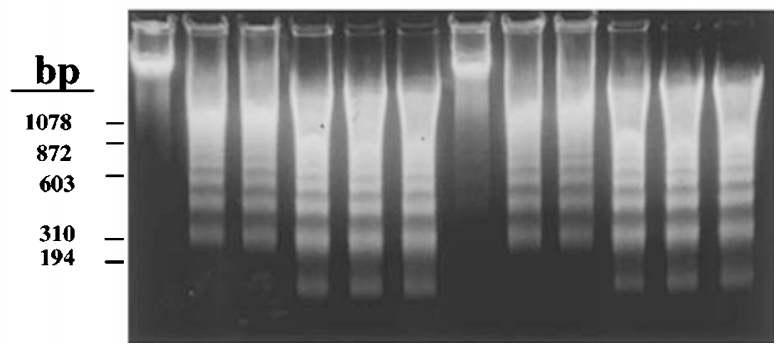

Figure 8 Internucleosomal DNA fragmentation induced by fluoride anions in THP-1 cells pretreated with or without PMA. THP-1 cells pre-treated with or without PMA $(100 \mathrm{nM})$ for $48 \mathrm{~h}$ were exposed to different concentrations of $\mathrm{NaF}$ for $24 \mathrm{~h}$. After the treatment, genomic DNA were extracted from the cells and analyzed for fragmentation by agarose gel electrophoresis. (a) DNA fragmentation in THP-1 cells. Lanes 1-6, THP-1 cells stimulated with 0 $5 \mathrm{nM} \mathrm{NaF}$; lanes 7-12, PMA-pretreated, fluoride-exposed THP-1 cells; (b) DNA fragmentation in Jurkat cells. Lanes 1-6, Jurkat cells stimulated with $0-$ $5 \mathrm{mM} \mathrm{NaF}$; lanes 7-12, PMA-pretreated, fluoride-exposed THP-1 cells

fragmentation into apoptotic bodies (Figure 9), resembling the situation observed in THP-1 and Jurkat cells treated with the agent. In contrast, $\mathrm{CHO}$ cells transfected with MSR cDNA showed only modest morphological changes (Figure 9d). When exposed to $5 \mathrm{mM} \mathrm{NaF}$ for $24 \mathrm{~h}$, nearly $80 \%$ of the $\mathrm{CHO}$ cells died (Figure 10). However, the death rate declined to $20 \%$ in MSR-expressing $\mathrm{CHO}$ cells after treatment with $\mathrm{NaF}$ at the same concentration (Figure 10). In situ $3^{\prime}$ end labeling of DNA fragments by TUNEL revealed that about $80 \% \mathrm{NaF}-$ treated wild-type $\mathrm{CHO}$ cells exhibited TUNEL-positive nuclei (Figure 11). However, compared to wild-type $\mathrm{CHO}$ cells, MSR-expressing $\mathrm{CHO}$ cells showed much less TUNEL staining $(15 \%, P<0.01)$, suggesting that MSR-expressing $\mathrm{CHO}$ cells resisted the apoptotic stimulation by fluoride anions. DNA agarose gel electrophoresis further demonstrated the occurrence of internucleosomal DNA fragmentation in $\mathrm{CHO}$ cells treated with $\mathrm{NaF}$. We observed that internucleosomal DNA fragmentation was markedly attenuated in $\mathrm{CHO}$ cells expressing MSR, compared to wild-type control cells, particularly when treated with $5 \mathrm{mM} \mathrm{NaF}$ (data not shown). Taken together, MSR expression by cDNA transfection appeared to confer resistance to NaF-induced apoptosis in $\mathrm{CHO}$ cells.

\section{Discussion}

The existence of functional macrophages in tissue relies on a balance between cell survival and death as well as by the number of monocytes that undergo terminal differentiation into macrophages. Most monocytes circulating in peripheral blood will die eventually by apoptosis if they do not mature and become robust, long-lived macrophages. ${ }^{24}$ This phenomenon suggests that monocyte differentiation is associated with the suppression of apoptosis. Recently, many have reported that certain gene products can regulate apoptosis. ${ }^{29}$ For instance, the Fas/FasL/caspase death-promoting system ${ }^{29}$ and the $\mathrm{Bcl}$ 2 anti-apoptotic oncogene ${ }^{31}$ have been reported to induce and inhibit apoptosis in many different cell types. However, we unexpectedly observed that in PMA-differentiated THP-1 monocytic cells, there were increases in expression of FasL and caspase-3, a key proteolytic enzyme in apoptosis, while $\mathrm{Bcl}-2$ levels were essentially unchanged. This points to the possibility that other gene families may play a role in the regulation of apoptosis during the process of monocyte-tomacrophage differentiation.

MSR is a multi-potential membrane protein expressed selectively in differentiated monomyeloid cell lineage, particularly in mature macrophages. ${ }^{1}$ Traditionally, MSR is recognized as a key receptor in the uptake of cholesterolrich lipoproteins and the formation of lipid-laden foam cells in the arterial wall with atherosclerosis. Recent studies have provided experimental evidence showing that this receptor may not merely mediate recognition and internalization of chemically modified LDL but may also participate in divalent cation-independent cell-to-cell adhesion, ${ }^{6,32}$ clearance of apoptotic cells ${ }^{7,33}$ and bacterial products, ${ }^{5}$ and even cellular signal transduction. ${ }^{34,35}$ The results from our current study provide evidence that documents a novel function of MSR, i.e., preventing apoptosis in differentiated monomyeloid cells. The first line of evidence supporting this MSR function emerged from the experiments on apoptosis of human THP-1 cells with or without expression of MSR. THP-1 cells cultured under baseline conditions do not express MSR. Treatment with such a transforming agent as phorbol esters leads to differentiation of the cells into macrophages and to expression of a great variety of genes including the death-promoting gene products (e.g., caspase-3 and FasL) and MSR. However, despite the death-gene expression, the MSR-expressing cells appeared resistant to apoptosis triggered by activation of G-proteins with fluoride anions. The second line of evidence is derived from the observation that PMA-treated Jurkat $T$ cells showed no difference in apoptosis from untreated Jurkat cells. In contrast to THP-1 cells that belong to the monomyeloid cell lineage, Jurkat T lymphoid cells cannot express MSR in response to PMA. After exposure to fluoride anions, both 

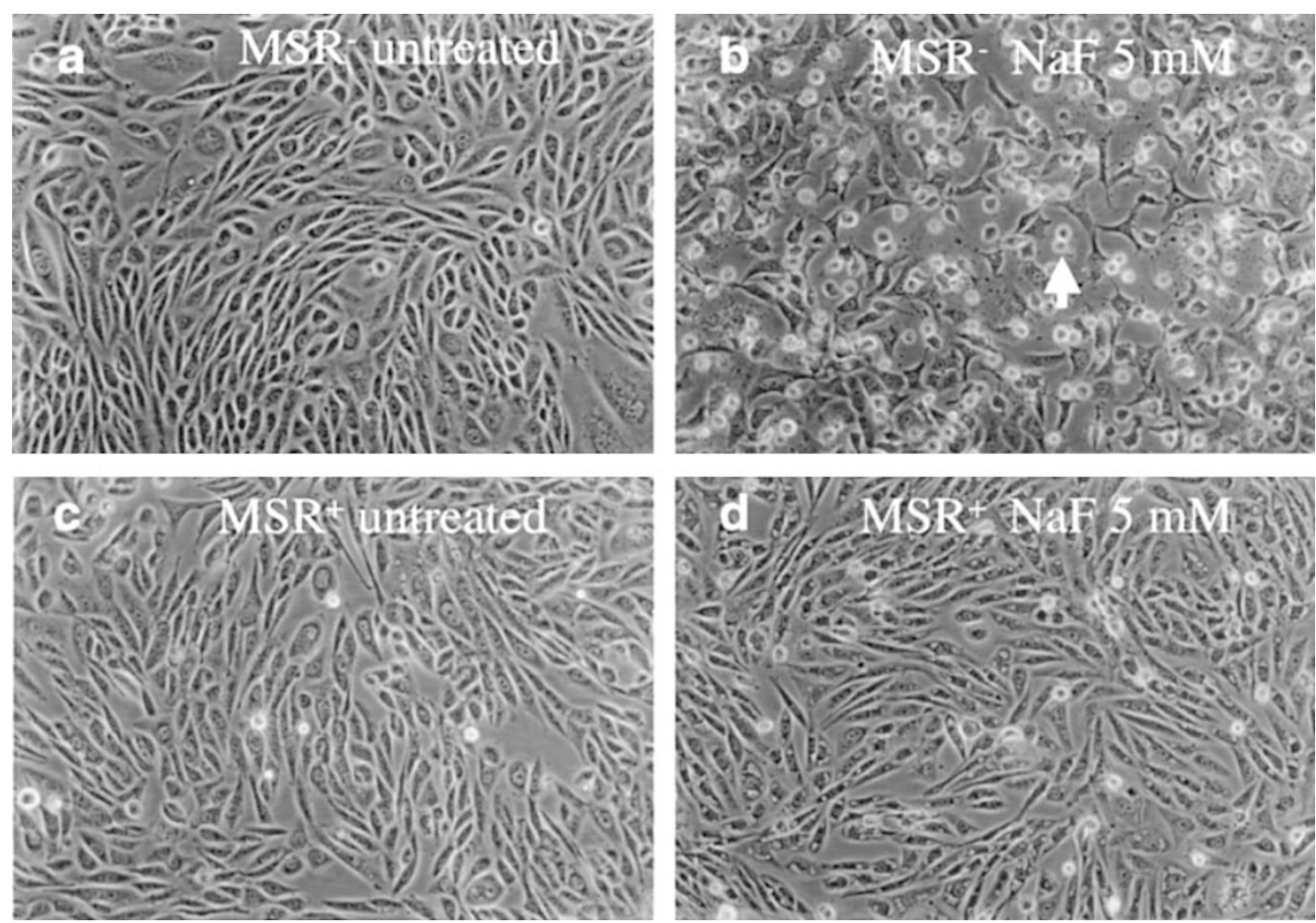

Figure 9 Morphology of NaF-treated CHO cells with or without expression of MSR by transfection. CHO cells with or without expression of MSR were treated with $\mathrm{NaF}(5 \mathrm{mM})$ for $24 \mathrm{~h}$. After treatment, cells were observed under a phase-contrast microscope with $40 \times$ objective. (a) untreated wild-type, MSR negative CHO cells; (b) NaF treated wild-type MSR-negative $\mathrm{CHO}$ cells; (c) untreated MSR-positive $\mathrm{CHO}$ cells; (d) NaF-treated MSR-positive $\mathrm{CHO}$ cells

PMA-treated and untreated Jurkat cells underwent apoptosis at the same rates, indicating that PMA treatment itself does not inhibit apoptosis. The third line of evidence supporting the role for MSR in preventing apoptosis comes from the studies of apoptosis in $\mathrm{CHO}$ cells with stable expression of MSR. Similar to MSR-expressing THP-1 macrophages, MSR-positive $\mathrm{CHO}$ cells are less sensitive to apoptosis. Thus, we conclude that de novo expression of MSR presents apoptosis triggered by activation of Gproteins with fluoride anions.

The reasons for using $\mathrm{CHO}$ cells rather than THP-1 cells as the host cells for MSR cDNA transfection are: (1) MSR expression in $\mathrm{CHO}$ cells is effective and functional similar to that in macrophages; (2) unlike $\mathrm{CHO}$ cells, THP-1 cells do not express the transfected cDNAleffectively and stably; and (3) wild-type $\mathrm{CHO}$ cells do not produce MSR while at high passages, THP-1 cells may differentiate and produce MSR.

MSR mediates clearance of many cytotoxic ligands that may trigger apoptosis of a variety of cells. ${ }^{36}$ Hence, theoretically, one may speculate that MSR reduces apoptosis by scavenging the cytotoxic substances generated during the development of apoptosis. In this study, we used fluoride anions, an apoptosis-promoting agent that does not act as the MSR ligand, to induce apoptosis. Although MSR may scavenge cytotoxic ligands produced endogenously by the cells exposed to fluoride anions, the

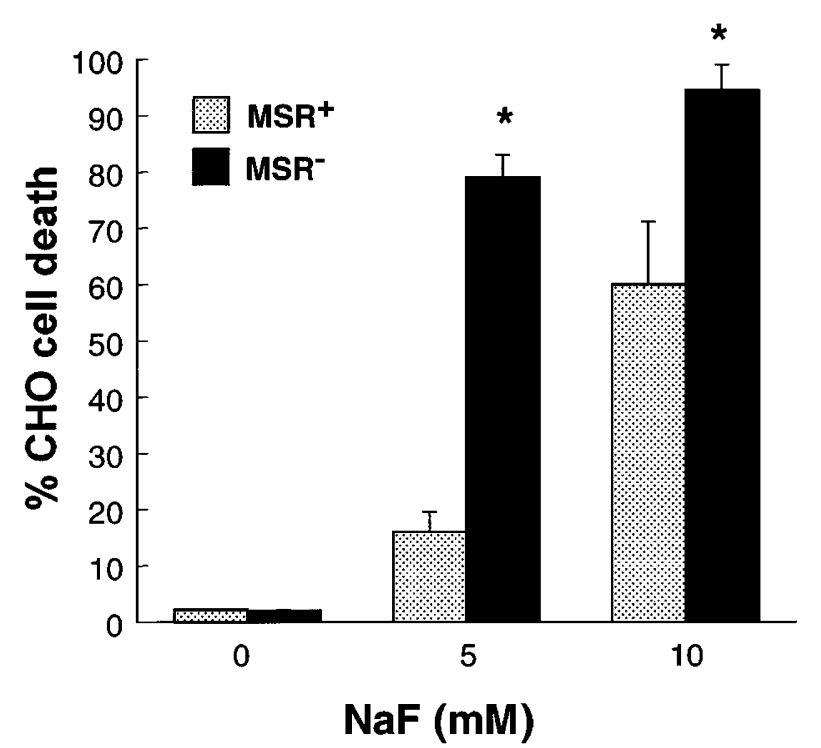

Figure 10 Fluoride-induced reduction in viability of $\mathrm{CHO}$ cells with or without expression of MSR. CHO cells with or without stable expression of MSR type I by cDNA transfection were exposed to $\mathrm{NaF}(0,5$ and $10 \mathrm{mM})$ for $24 \mathrm{~h}$. Cell viability was determined by fluorescent microscopy with a combination of acridine orange and ethidium bromide. More than 200 cells were counted and the percentage of dead cells calculated by dividing the number of dead cells by the total number of cells. Data represent means + S.D. $(n=4) .{ }^{*} P<0.05$ 

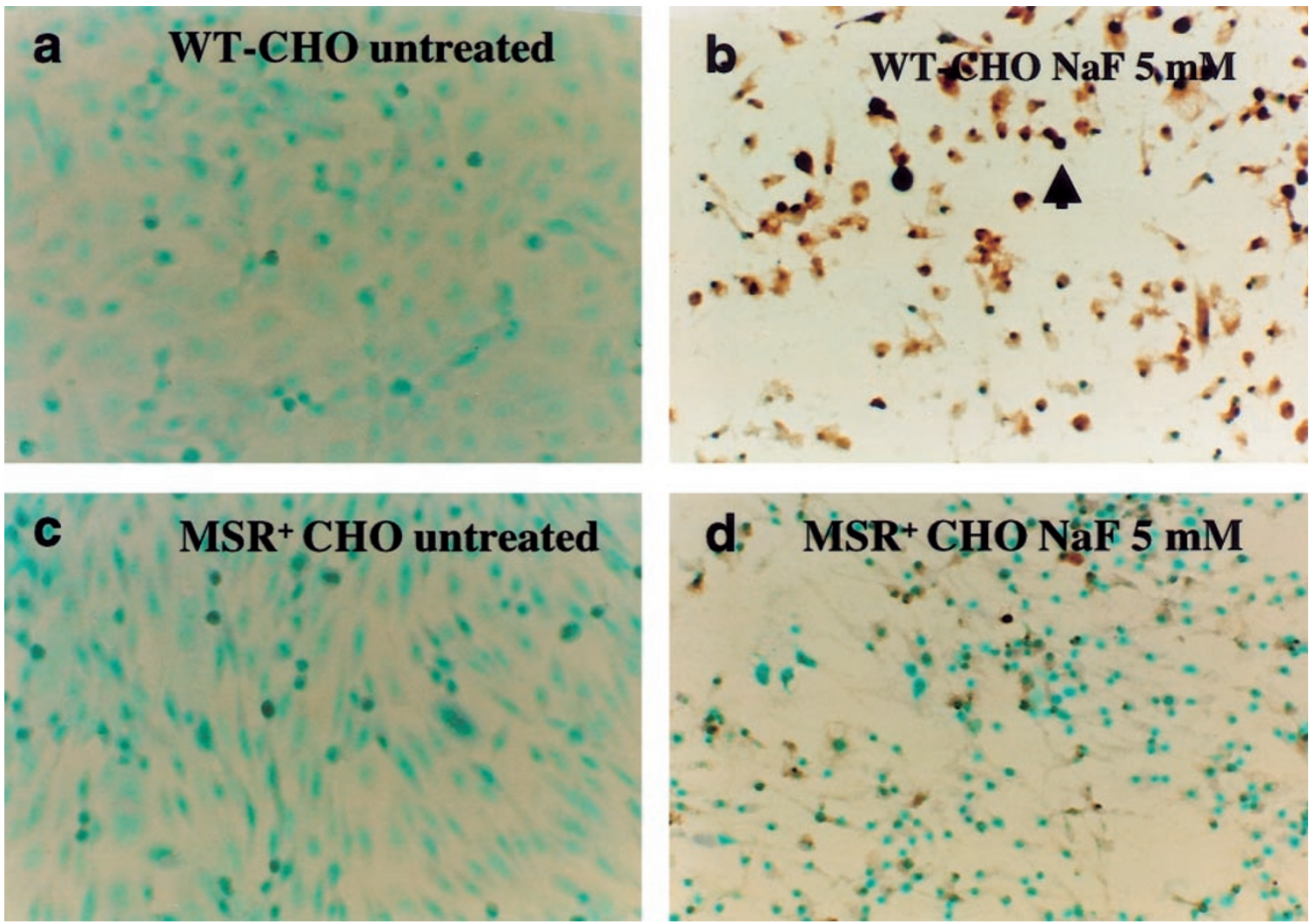

Figure 11 In situ detection of DNA fragments by TUNEL in CHO cells with or without expression of MSR. CHO cells with or without expression of MSR were treated with $\mathrm{NaF}(5 \mathrm{mM})$ for $24 \mathrm{~h}$. Fragmented DNA was labeled by TUNEL with an ApoTaq kit (Oncor). Nuclear counterstaining was performed with methyl green. (a) untreated wild-type cells; (b) NaF-treated cells; (c) untreated MSR-expressing cells; (d) NaF-treated MSR-expressing cells

main mechanism for the reduction in apoptosis of THP-1 cells and $\mathrm{CHO}$ cells expressing MSR may be attributed in part to the attenuation of death signals crossing the cellular membrane. This receptor may not serve as a survivalsignal deliver. Its protective effect on macrophages may be mediated by a complex interaction between MSR and other membrane signals molecules such as G-proteins.

The global activation of the heterotrimers of membranebound G-proteins has been reported as a potential mechanism underlying induction of apoptosis by fluoride anions. ${ }^{27,28,37}$ It has been known for several decades that fluoride anions can react with aluminium ions forming AIFx complexes that mimic the gamma phosphate of a GTP and thereby activate cellular GTP-binding proteins. ${ }^{38}$ Fluoride anions may form a complex with a trace of aluminium ions from glassware, which can activate G-proteins. ${ }^{39}$ The exact mechanism for MSR regulation of G-protein transmembrane signaling is unclear. Increased density of MSR in the plasma membrane may prevent formation of the complex or remove the negatively charged G alpha (GDP-AIF4). This point is supported by the increased resistance to fluoride anion-induced apoptosis in MSR-expressing cells, suggesting that MSR may diminish the death signaling through the G-protein pathway.

PMA is a potent activator of PKC in monocytes/ macrophages as well as in other cell types. This raises the question as to whether PKC is involved in the regulation of macrophage apoptosis. Munn et $a^{24}$ reported that treatment with PMA induces apoptosis of human monocyte-derived macrophages in culture. The induction of apoptosis can be inhibited by the PKC inhibitor staurosporine. However, in many other cell systems, the activation of PKC has been shown to suppress apoptosis. ${ }^{40}$ In this study, we observed no significant cell death in PMAtreated THP-1 monocytic cells. Instead, the treated cells exhibited resistance to apoptotic attack by fluoride anions. Moreover, Jurkat T cells stimulated with PMA did not show any increase in apoptosis as compared to untreated Jurkat cells. Interestingly, recent work by Hsu et $a^{\beta 5}$ has shown that binding of MSR ligands to MSR may activate PKC, leading to expression of urokinase-type plasminogen activator in THP-1 cells. Finally, as shown in this study, $\mathrm{CHO}$ cells with stable expression of MSR are much less sensitive to apoptosis triggered by fluoride anions. Thus, it is likely that at different stages of differentiation, monocytes/ macrophages exhibit different responses to apoptotic stimulation that may or may not be regulated by PKC.

MSR regulation of apoptosis of macrophages may be significant in the pathophysiology of macrophages. The longevity of MSR-producing macrophages may be important for maintaining homeostasis, as macrophages belong to the primary defense system that scavenges denatured, 
cytotoxic, and/ or cytostatic macromolecules. However, apoptosis may also be used as a potential means by which macrophages kill intracellular pathogenic microorganisms in a suicidal fashion. A broad range of facultative intracellular pathogens, e.g., mycobacteria, fungi, and protozoa, have been found in the macrophage 'shelter'. ${ }^{41}$ Frequently, these microorganisms are highly resistant to antibiotics. To eliminate them from the tissue, macrophages must be primed by proinflammatory cytokines such as interferon-gamma and tumor necrosis factors. Interestingly, the two cytokines both have been shown to down-regulate MSR. ${ }^{15,17}$ The cytokine-activated, MSR-dime macrophages likely become vulnerable to apoptotic attack by products of cytotoxic $T$ cells such as the Fas-FasL death-signaling molecules. $^{29}$

The class-A macrophage MSR is also important for the pathogenesis of atherosclerosis. Blood-borne monocytes infiltrate into the intima of the artery, where they differentiate into macrophages and express substantial amounts of MSR. Previous reports ${ }^{10,11}$ have demonstrated that many lipid-laden foamy macrophages display stronger immunostains for MSR in advanced atherosclerotic lesions, particularly in the necrotic lipid core area, where large quantities of cytotoxic substances, including oxLDL, accumulate. However, in spite of the harsh extracellular environment in the plaque lipid core, considerable numbers of macrophages and macrophage-derived foam cells survive and accumulate, contributing to the development of the plaques. Although many other factors may play a role in the survival of macrophages and in preventing the cells from apoptosis, our current data strongly suggest that expression of MSR may be one of the key events for survival of certain macrophages and macrophage-derived foam cells in atherosclerotic lesions.

\section{Materials and Methods}

\section{Reagents}

Phorbol 12-myristate 13-acetate (PMA), RNase A, T4 polynucleotide kinase, phenylmethylsulfonyl fluoride (PMSF), and the DNA-binding fluorochromes acridine orange and ethidium bromide were purchased from Sigma, and YOYO-1 was purchased from Molecular Probes. RPMI 1640 and DMEM-F12 media were obtained from GIBCO. Sodium fluoride (NaF), phenol, and chloroform were obtained from Fisher. FITC-conjugated rabbit anti-mouse IgG was purchased from Amersham. Kits for RNase protection assay and for in situ labeling of DNA ends were purchased from Ambion and Oncor, respectively. Antibodies against CPP32, Fas ligand, FADD (Fas-associated death domain), and $\mathrm{Bcl}-2$ were obtained from Transduction.

\section{Cell cultures}

Human THP-1 monomyeloid cells, human Jurkat T lymphoid cells and Chinese Hamster Ovary (CHO) fibroblast cells were obtained from the American Type Culture Collection (ATCC, Rockville, MD, USA). Both THP-1 and Jurkat cells were cultured in RPMI-1640 medium (GIBCOBRL, Grand Island, NY, USA), supplemented with $10 \%$ fetal bovine serum (FBS, Sigma, St. Louis, MO, USA, 100 units $/ \mathrm{ml}$ penicillin, and $100 \mu \mathrm{g} / \mathrm{ml}$ streptomycin. $\mathrm{CHO}$ cells were maintained in DMEM-F12 medium, supplemented with 10\% FBS and antibiotics. For treatment with PMA and sodium fluoride, cells cultured in 6-well plates were pretreated with PMA $(100 \mathrm{nM})$ for $48 \mathrm{~h}$ to induce expression of MSR. Thereafter, the cells were washed three times in phosphate-buffered saline (PBS) and exposed to $\mathrm{NaF}$ at a range of $1-$ $10 \mathrm{mM}$ for different times.

\section{Determination of cell viability}

Cell viability was assessed by fluorescence microscopy with the nucleic acid-binding fluorochromes acridine orange and ethidium bromide using a previously described method with modification. ${ }^{42,43}$ The cells were incubated on ice with acridine orange $(10 \mu \mathrm{g} / \mathrm{ml})$ and ethidium bromide $(0.5 \mu \mathrm{g} / \mathrm{ml})$. After staining for $5 \mathrm{~min}$, the cells were observed under a Nikon fluorescence microscope. Viable cells showed green fluorescent nuclei, while the nonviable cells exhibited red or orange fluorescent nuclei. For each sample, at least 200 cells were counted in different high-power fields. The percentage of dead cells was determined by the following formula: $\%$ dead cells $=100 \times$ (number of dead cells)/(total number of cells).

\section{Confocal scanning microscopy}

Morphology of THP-1 cells stained with a combination of acridine orange and ethidium bromide was characterized by fluorescent confocal scanning microscopy. THP-1 cells were incubated with or without $\mathrm{NaF}$ in 6 -well plates and then collected in a $1.5 \mathrm{~mL}$ microfuge tube with the fluorescent dyes for $3 \mathrm{~min}$. After staining, cells were subjected to examination under a Bio-Rad scanning confocal microscope (MRC-1024 Krypton/Argon Confocal Imaging System, Bio-Rad Laboratories, Inc.).

\section{Fluorescent flow cytometry}

Cells treated or not with PMA were analyzed for MSR expression by flow cytometry. The cells were washed with ice-cold PBS and incubated with mouse anti-human MSR monoclonal antibody on ice for $1 \mathrm{~h}$. After rinsing with PBS, the cells were incubated with second goat-anti-mouse IgG conjugated with FITC (Amersham) for $30 \mathrm{~min}$, washed in PBS, and suspended in PBS with $5 \mu \mathrm{g} / \mathrm{ml}$ propidium iodide. After labeling, the cells were subjected to analysis by flow cytometry. The MSR signals were recorded in the FL1 channel (green fluorescence), while dead cells were identified by the FL2 channel (red fluorescence), on a FACScalibur flow cytometer (Becton Dickinson and Co., Mountain View, CA, USA). Data were analyzed using the CellQuest program.

\section{Immunoblotting}

Total proteins extracted from cells treated or not with PMA were used for immunoblotting. Briefly, the cells were lysed in a lysis buffer $(5 \mathrm{mM}$ Tris- $\mathrm{HCl}$ at $\mathrm{pH} 7.5,2 \mathrm{mM}$ EDTA, $1 \%$ Triton X-100, $1 \mathrm{mM}$ PMSF). The protein concentration was determined using the BCA protein assay kit (Pierce, Rockford, IL, USA). $30 \mu \mathrm{g}$ proteins were separated by electrophoresis on 7.5\% SDS-PAGE and transferred onto a PVDF membrane (Micron Separations). After transferring, the membrane was blocked in $4 \%$ fat-free milk in PBS, and then probed with antibodies to MSR, Fas, FasL, CPP32 (caspase-3), FADD, and Bcl-2. Bound primary antibody was detected with horseradish peroxidase conjugated goat-anti-mouse $\operatorname{lgG}$. The membrane was developed by using an Amersham (Buckinghamshire, UK) ECL Western blotting kit. 


\section{In situ labeling of DNA fragments}

Cells undergoing apoptosis generate abundant DNA fragments in their nuclei. In situ detection of DNA fragments by terminal deoxyribonucleotide transferase (TdT)-mediated dUTP nick end labeling (TUNEL) was performed as previously described. ${ }^{43-45}$ THP-1 cells cultured on 8-well chamber-slides were induced to differentiate into macrophages by treatment with $100 \mathrm{nM}$ PMA for $48 \mathrm{~h}$. The cells were then treated with $\mathrm{NaF}$ or left untreated. At the end of incubation, the cells were fixed in $4 \%$ paraformaldehyde and smeared on glass slides. After washing in PBS, cells were incubated with $2 \% \mathrm{H}_{2} \mathrm{O}_{2}$ in PBS to inactivate endogenous peroxidase. Digoxigenin-conjugated dUTP was incorporated into the DNA $3^{\prime}$ end with TdT using an ApoTag in situ apoptosis detection kit (Oncor, Inc). The presence of digoxigenin-labeled DNA fragments was determined using a peroxidase-conjugated antibody against digoxigenin. The chromogenic substance DAB was used as a substrate for visualization of the immunostaining. The percentage of TUNEL-positive cells was calculated by dividing the number of positive cells by the total number of cells.

\section{DNA isolation and electrophoresis}

To determine the sizes of DNA fragments, genomic DNA was isolated and analyzed by agarose gel electrophoresis. Since cells undergoing apoptosis are frequently detached from culture dishes, cells suspending in the medium were also collected. Cells $\left(>10^{6}\right)$ were lysed in $1 \mathrm{ml}$ of the DNA extraction buffer containing $10 \mathrm{mM}$ Tris-HC (pH 8.0), $10 \mathrm{mM}$ EDTA (pH 8.0), $100 \mathrm{mM} \mathrm{NaCl}$, and 0.5\% SDS. The cellular lysates were incubated with $100 \mu \mathrm{g} / \mathrm{ml}$ proteinase $\mathrm{K}$ at $56^{\circ} \mathrm{C}$ for $3 \mathrm{~h}$. The mixtures were extracted with phenol/chloroform, precipitated with isopropanol $(1: 1 \mathrm{v} / \mathrm{v})$ at $-20^{\circ} \mathrm{C}$ for $2 \mathrm{~h}$. After centrifugation at $13000 \times g$ for $20 \mathrm{~min}$, the DNA pellet was dissolved in $10 \mathrm{mM}$ Tris-HCl buffer with $1 \mathrm{mM}$ EDTA. RNA contaminating the preparation of genomic DNA was removed by incubation with RNase A $(25 \mathrm{ng} / \mu \mathrm{l})$ for $30 \mathrm{~min}$ at $37^{\circ} \mathrm{C}$ followed by re-extraction with phenol/chloroform. DNA electrophoresis was carried out in $2 \%$ agarose gels containing $0.5 \mu \mathrm{g} /$ $\mathrm{ml}$ ethidium bromide, and DNA fragments were visualized by exposing the gel to ultraviolet light.

Preparation of nuclear extracts Cells treated with or without PMA were collected into a $15 \mathrm{ml}$ tube and centrifuged at $1500 \times \mathrm{g}$ for $5 \mathrm{~min}$. After removing the supernatant, the cell pellet was resuspended in $400 \mu$ l of buffer A (10 mM HEPES, pH 7.9; 10 mM KCl; 0.1 mM EDTA; $0.1 \mathrm{mM}$ EGTA; $1 \mathrm{mM}$ DTT; $1 \mathrm{mM}$ PMSF). The cells were allowed to swell on ice for $15 \mathrm{~min}$ and than were mixed with $25 \mu$ l Nonidet NP-40 by vortexing for $10 \mathrm{~s}$. The homogenate was centrifuged at $10000 \times g$ for $5 \mathrm{~min}$. The resulting nuclear pellet was resuspended in $50 \mu \mathrm{l}$ of icecold buffer $\mathrm{C}$ (20 mM HEPES, pH 7.9; $0.42 \mathrm{M} \mathrm{NaCl} ; 1 \mathrm{mM}$ EDTA; $1 \mathrm{mM}$ EGTA, $1 \mathrm{mM}$ DTT, and $1 \mathrm{mM}$ PMSF). The tube was vigorously shaken at $4^{\circ} \mathrm{C}$ for $30 \mathrm{~min}$. The nuclear extract was centrifuged at $10000 \times \mathrm{g}$ for $5 \mathrm{~min}$ at $4^{\circ} \mathrm{C}$ in a microcentrifuge. The protein concentration of cell extract was determined with the Pierce Micro BCA Protein Assay Kit.

\section{Gel electrophoretic mobility shift assay (EMSA)}

EMSA was performed as previously reported. ${ }^{21}$ Briefly, an oligonucleotide (5'-AACGCAGGAATGTGTCATTTCCTTT- $\left.3^{\prime}\right)$ coding for the AP1/ets-like cis-element extending from -10 to $+15 \mathrm{bp}$ of the human MSR promoter labeled with $\gamma-{ }^{32} \mathrm{P}$-ATP and T4 polynucleotide kinase was mixed with cell nuclear extracts. The binding reaction between the oligonucleotide and nuclear proteins was performed in $12.5 \mu \mathrm{l}$ reaction mixtures containing $4 \mathrm{mM}$ Tris- $\mathrm{HCl}(\mathrm{pH}$ 7.9), $10 \mathrm{mM}$ HEPES (pH 7.9), $1 \mathrm{mM}$ DTT, $1 \mathrm{mM}$ EDTA, $60 \mathrm{mM} \mathrm{KCl,}$
$0.2 \mathrm{mg} / \mathrm{ml}$ poly ( $\mathrm{dl}-\mathrm{dC}$ ), and $10 \%$ glycerol with $6 \mu \mathrm{g}$ cell extract protein. The reaction mixture was incubated at room temperature for $30 \mathrm{~min}$ and then loaded directly onto $6 \%$ polyacrylamide gel with a TAE buffer containing $6.7 \mathrm{mM}$ Tris- $\mathrm{HCl}(\mathrm{pH} 7.5), 3.3 \mathrm{mM}$ sodium acetate, and $1 \mathrm{mM}$ EDTA. The electrophoresis was carried out at a constant voltage of 150 volts at room temperature for $1-2 \mathrm{~h}$, and thereafter gels were dried and exposed to X-ray film at $-80^{\circ} \mathrm{C}$ overnight.

\section{RNase protection assay}

Total RNA was isolated from cells by using acid guanidinium thiocyanate-phenol-chloroform extraction as described by Chomczynski and $\mathrm{Sacchi}^{46}$ with modifications. Cells were lysed in $0.5 \%$ sodium lauryl sulphate, $4 \mathrm{M}$ guanidinium isothiocyanate, $100 \mu \mathrm{M} 2$ mercaptoethanol, and $25 \mathrm{mM}$ sodium citrate $(\mathrm{pH} \mathrm{7.0)}$. After addition of 0.1 volume $2 \mathrm{M}$ sodium acetate $\mathrm{pH} 4.0$, RNA was extracted from the cell lysates in phenol $(1: 1 \mathrm{v} / \mathrm{v})$ with 0.2 volume chloroformisoamyl alcohol (49:1). CRNA probes for type I and type II MSR mRNA were synthesized respectively. Type I-specific (279 bp) and type II-specific (229 bp) DNA fragments were synthesized from a plasmid containing full-length human MSR cDNA by polymerase chain reaction (PCR) with primers selectively recognizing type I or type II MSR cDNA. These PCR-generated cDNA fragments of MSR types I and II were subcloned into a PCR II vector. The plasmids containing the MSR I- and MSR II-specific CDNA fragments were linearized, treated with proteinase $\mathrm{K}$ and extracted with phenol/ chloroform/ isoamylalcohol $(25: 24: 1)$. The linearized plasmid constructs were incubated with $\left[{ }^{32} \mathrm{P}\right]$-UTP (NEN Research Products, Boston, MA, USA) and T7 or SP6 RNA polymerase to synthesize the MSR riboprobes, using a Riboprobe Gemini kit (Promega, Madison, WI, USA). The labeled transcripts were treated with DNase I to remove DNA and then purified by extraction with phenol/chloroform/isoamylalcohol. In addition, for control experiments, a glyceraldehyde-3-phosphate dehydrogenase (GAPDH) cRNA probe was prepared. An RPA II kit (Ambion, Austin, TX, USA) was used to perform the RNase protection assays.

\section{Statistics}

Difference in means was determined by Student's $t$-test. For analysis of multiple groups of data, the ANOVA program was used. A significance level was established when the $P$ value was less than 0.05 .

\section{Acknowledgements}

This study is supported by NIH/NIBLH grant HL-59496 and an AHA-Penn Grant-In-Aid award. We thank Stephen F Vatner, MD, for constructive discussion and support.

\section{References}

1. Kodama T, Doi T, Suzuki H, Takahashi K, Wada Y and Gordon S (1996) Collagenous macrophage scavenger receptors. Curr. Opin. Lipidol. 7: 287-291

2. Freeman MW (1997) Scavenger receptors in atherosclerosis. Curr. Opin. Hematol. 4: $41-47$

3. Hampton RY, Golenbock DT, Penman M, Krieger M and Raetz CR (1991) Recognition and plasma clearance of endotoxin by scavenger receptors. Nature 352: 342-344

4. Freeman MW (1994) Macrophage scavenger receptors. Curr. Opin. Lipidol. 5: $143-148$ 
5. Haworth R, Platt N, Keshav S, Hughes D, Darley E, Suzuki H, Kurihara $Y$, Kodama T and Gordon S (1997) The macrophage scavenger receptor type A is expressed by activated macrophages and protects the host against lethal endotoxic shock. J. Exp. Med. 186: 1431-1439

6. Fraser I, Hughes D and Gordon S (1993) Divalent cation-independant macrophage adhesion inhibited by monoclonal antibody to murine scavenger receptor. Nature 364: 343-346

7. Platt N, Suzuki H, Kurihara Y, Kodama T and Gordon S (1996) Role for the class A macrophage scavenger receptor in the phagocytosis of apoptotic thymocytes in vitro. Proc. Natl. Acad. Sci. USA 93: 12456-12460

8. Pearson AM (1996) Scavenger receptors in innate immunity. Curr. Opin. Immunol. 8: 20-28

9. Geng Y-J and Hansson GK (1995) High endothelial cells of postcapillary venules express the scavenger receptor in human peripheral lymph nodes. Scand. J. Immunol. 42: 289-296

10. Geng Y-J, Holm J, Nygren S, Bruzelius M, Stemme S and Hansson GK (1995) Expression of the macrophage scavenger receptor in atheroma. Relationship to immune activation and the T-cell cytokine interferon-gamma. Arterioscler. Thromb. Vasc. Biol. 15: 1995-2002

11. Geng Y-J, Kodama T and Hansson GK (1994) Differential expression of scavenger receptor isoforms during monocyte-macrophage differentiation and foam cell formation. Arterioscler. Thromb. 14: 798-806

12. Naito M, Kodama T, Matsumoto A, Doi T and Takahashi K (1991) Tissue distribution, intracellular localization, and in vitro expression of bovine macrophage scavenger receptors. Am. J. Pathol. 139: 1411-1423

13. Naito M, Suzuki H, Mori T, Matsumoto A, Kodama T and Takahashi K (1992) Coexpression of type I and type II human macrophage scavenger receptors in macrophages of various organs and foam cells in atherosclerotic lesions. Am. J. Pathol. 141: 591-599

14. Clinton SK, Underwood R, Hayes L, Sherman ML, Kufe DW and Libby P (1992) Macrophage colony-stimulating factor gene expression in vascular cells and in experimental ahd human atherosclerosis. Am. J. Pathol. 140: 301-316

15. Geng YJ and Hansson GK (1992) Interferon-gamma inhibits scavenger receptor expression and foam cell formation in human monocyte-derived macrophages. J. Clin. Invest. 89: 1322-1330

16. van Lenten BJ and Fogelman AM (1992) Lipopolysaccharide-induced inhibition of scavenger receptor expression in human monocyte-macrophages is mediated through tumor necrosis factor-alpha. J. Immunol. 148: 112-116

17. Hsu HY, Nicholson AC and HajjarDP (1996) Inhibition of macrophage scavenger receptor activity by tumor necrosis factor-alpha is transcriptionally and posttranscriptionally regulated. J. Biol. Chem. 271: 7767-7773

18. Horvai A, Palinski W, Wu H, Moulton KS, Kalla Kand Glass CK (1995) Scavenger receptor $A$ gene regulatory elements target gene expression to macrophages and to foam cells of atherosclerotic lesions. Proc. Natl. Acad. Sci. USA 92:53915395

19. Moulton KS, Semple K, Wu H and Glass CK (1994) Cell-specific expression of the macrophage scavenger receptor gene is dependent on PU.1 and a composite AP-1/ets motif. Mol. Cell Biol. 14: 4408-4418

20. Wu H, Moulton K, Horvai A, Parik S and Glass CK (1994) Combinatorial interactions between AP-1 and ets domain proteins contribute to the developmental regulation of the macrophage scavenger receptor gene. Mol. Cell Biol. 14: 2129-2139

21. Liao HS, Kodama T, Doi T, Emi M, Asaoka H, Itakura H and Matsumoto A (1997) Novel elements located at -504 to -399 bp of the promoter region regulated the expression of the human macrophage scavenger receptor gene in murine macrophages. J. Lipid. Res. 38: 1433-1444

22. Managan DF, Welch GR and Wahl SM (1991) Lipooolysaccharide, tumor necrosis factor-a, and IL-1beta prevent programmed cell death (apoptosis) in human peripheral blood monocytes. J. Immunol. 146: 1541-1546

23. Managan DF and Wah SM (1991) Differential regulation of human monocyte programmed cell death (apoptosis) by chemotactic factors and pro-inflammatory cytokines. J. Immunol. 155: 4917-4925

24. Munn DH, Beall AC, Song D, Wrenn RW and Throckmorton DC (1995) Activation-inducedapoptosis in human macrophages: developmental regulation of a novel cell death pathway by macrophage colony-stimulating factor and interferon gamma. J. Exp. Med. 181: 127-136
25. Kiener PA, Davis PM, Starling GC, Mehlin C, Klebanoff SJ, Ledbetter JA and Liles WC (1997) Differential induction of apoptosis by Fas-Fas ligand interactions in human monocytes and macrophages. J. Exp. Med. 185: 1511-1516

26. Richardson BC, Lalwani ND, Johnson KJ and Marks RM (1994) Fas ligation triggers apoptosis in macrophages but not endothelial cells. Eur. J. Immunol. 24: $2640-2645$

27. Hirano S and Ando M (1996) Apoptotic cell death following exposure to fluoride in rat alveolar macrophages. Arch. Toxicol. 70: 249-251

28. Loweth AC, Williams GT, Scarpello JH and Morgan NG (1996) Heterotrimeric Gproteins are implicated in the regulation of apoptosis in pancreatic beta-cells. Exp. Cell Res. 229, 69-76

29. Nagata $S$ (1997) Apoptosis by death factor. Cell 88: $355-365$

30. Schlegel J, Peters I, Orrenius S, Miller DK, Thornberry NA, Yamin TT and Nicholson DW (1996) CPP32/apopain is a key interleukin 1 beta converting enzyme-like protease involved in Fas-mediated apoptosis. J. Biol. Chem. 271: $1841-1844$

31. Reed JC (1997) Double identity for proteins of the Bcl-2 family. Nature 387: $773-$ 776

32. Fraser I, Doyle A, Hughes D and Gordon S (1994) Use of surface molecules and receptors for studying macrophages and mononuclear phagocytes. J. Immunol. Methods. 174: 95-102

33. Savill JS, Henson PM and Haslett C (1989) Phagocytosis of aged human neutrophils by macrophages is mediated by a novel 'charge-sensitive' recognition mechanism. J. Clin. Invest. 84: 1518-1527

34. Fong LG (1996) Modulation of macrophage scavenger receptor transport by protein phosphorylation. J. Lipid Res. 37: 574-587

35. Jsu HY, Hajjar DP, Khan KM and Falcone DJ (1998) Ligand binding to macrophage scavenger receptor-A induces urokinase-type plasminogen activator expression by a protein kinase-dependent signaling pathway. J. Biol. Chem. 273: $1240-1246$

36. Krieger M and Herz J (1994) Structures and functions of multiligand lipoprotein receptors: macrophage scavenger receptors and LDL receptor-related protein (LRP). Annu. Rev. Biochem. 63: 601-637

37. Schwarze PE, Johnsen NM, Samuelsen JT, Thrane EV, Lund K, Lag M, Refsnes M, Kongerud J, Becher R, Boe J, Holme JA and Wiger R (1996) The use of isolated lung cells in in vitro pulmonary toxicology: studies of DNA damage, apoptosis and alteration of gene expression. Cent. Eur. J. Public Health. Suppl 4: $6-10$

38. Bigay J, Deterre P, Pfister C and Chabre M (1987) Fluoride complexes of aluminium or beryllium act on $\mathrm{G}$-proteins as reversibly bound analogues of the gamma phosphate of GTP. EMBO J. 6: 2907-2913

39. Tesmer JJ, Berman DM, Gilman AG and Sprang SR (1997) Structure of RGS4 bound to AlF4-activated G (i alpha): Stabilization of the transition state for GTP hydrolysis. Cell 89: $251-261$

40. McConkey DJ, Orrenius S and Jondal M (1990) Cell signaling in programmed cell death (apoptosis). Immunol. Today 11: 120-121

41. Small PLC, Ramakrishnan L and Falkow S (1994) Remodeling schemes of intracellular pathogens. Science 263: 637-639

42. Geng YJ, Hellstrand K, Wennmalm A and Hansson GK (1996) Apoptotic death of human leukemic cells induced by vascular cells expressing nitric oxide synthase in response to gamma-interferon and tumor necrosis factor-alpoha. Cancer Res. 56: $866-874$

43. Geng Y-J, Wu Q, Muszynski M, Hansson GK and Libby P (1996) Apoptosis of vascular smooth muscle cells induced by in vitro stimulation with interferongamma, tumor necrosis factor-alpha, and interleukin-1 beta. Arterioscler. Thromb. Vasc. Biol. 16: 19-27

44. Geng Y-J and Libby P (1995) Evidence for apoptosis in advanced human atheroma: colocalization with interleukin-1b converting enzyme. Am. J. Pathol. 147: $251-266$

45. Geng Y-J, Henderson EL, Levesque EB, Muszynski M and Libby P (1997) Fas is expressed in human atherosclerotic intima and mediates apoptosis of cultured human smooth muscle cells. Arterioscler. Thromb. Vasc. Biol. 17: 2200-2208

46. Chomczynski Pand SacchiN (1987) Single-step method of RNA isolation by acid quanidinium thiocyanate-phenol-chloroform extraction. Anal. Biochem. 162: $156-160$ 